African Crop Science Journal by African Crop Science Society is licensed under a Creative Commons Attribution 3.0 Uganda License. Based on a work at www.ajol.info/ and www.bioline.org.br/cs DOI: https://dx.doi.org/10.4314/acsj.v27i3.7

\title{
PHENOTYPIC DIVERSITY OF PUMPKINS FROM WESTERN KENYA USING FRUIT MORPHOLOGICAL CHARACTERS
}

\author{
L.A. NYABERA ${ }^{1}$, S.M. RUNO ${ }^{1}$, I.W. NZUKI ${ }^{2,3}$ and P.W. AMWAYI ${ }^{2}$
}

\author{
${ }^{1}$ Department of Biochemistry and Biotechnology, Kenyatta University, Nairobi, Kenya \\ ${ }^{2}$ Department of Biochemistry and Biotechnology, The Technical University of Kenya, \\ Nairobi, Kenya \\ ${ }^{3}$ Biosciences Eastern and Central Africa (BecA), International Livestock Research Institute (ILRI), \\ Nairobi, Kenya \\ Corresponding author: peris.amwayi@gmail.com
}

(Received 16 July 2018; accepted 23 July 2019)

\begin{abstract}
Pumpkin (Cucurbita spp.) is an important indigenous crop in Africa with high nutritional, medicinal and economic value. In Kenya, pumpkins still remain underutilised and neglected; as a result may face extinction. In this study, morphological diversity of eighty pumpkin samples from eight counties in western Kenya were evaluated based on qualitative and quantitative fruit characters, using International Plant Genetic Resources Institute (IPGRI) minimum descriptor for Cucurbitacea as a scoring guide. Principal component analysis (PCA) and cluster analysis of the morphological data, was conducted using XLSTAT 2017 software. Results showed that the first four principal components (PCs) were the most significant, accounting for a total variation of 73.85\%. A scatterplot of the first two PCs accounted for $50.19 \%$ of the total variation. Majority of the samples were densely scattered. Cluster analysis and the similarity dendrogram grouped the samples into five clusters. The most effective characters for discriminating pumpkin fruits were fruit diameter, fruit width, fruit length, and length to diameter ratio. These may be described as fruit yield characters with desirable traits for productivity, therefore, presenting a good opportunity for breeders to improve pumpkins and for screening and selecting germplasms.
\end{abstract}

Key Words: Cucurbita spp., IPGRI, morphological diversity

\section{RÉSUMÉ}

La citrouille (Cucurbita spp.) est une culture indigène importante en Afrique à haute valeur nutritionnelle, médicinale et économique. Au Kenya, les citrouilles restent encore sous-utilisées et négligées; en conséquence, peuvent faire face à l'extinction. Dans cette étude, la diversité morphologique de quatrevingts échantillons de citrouille provenant de huit comtés de l'ouest du Kenya a été évaluée sur la base de caractères qualitatifs et quantitatifs des fruits, en utilisant le descripteur minimal de l'Institut de ressources phytogénétiques de l'IPGRI pour les cucurbitacées comme guide de notation. L'analyse 
en composantes principales (ACP) et l'analyse par grappes des données morphologiques ont été réalisées à l'aide du logiciel XLSTAT 2017. Les résultats ont montré que les quatre premières composantes principales (PC) étaient les plus significatives, représentant une variation totale de $73,85 \%$. Un diagramme de dispersion des deux premiers composantes principales représentait 50,19\% de la variation totale. La majorité des échantillons étaient densément dispersés. L'analyse en groupes et le dendrogramme de similarité ont regroupé les échantillons en cinq groupes. Les caractères les plus efficaces pour distinguer les fruits à la citrouille étaient le diamètre, la largeur, la longueur et le rapport longueur / diamètre du fruit. Celles-ci peuvent être décrites comme des caractères de rendement en fruits avec des caractéristiques souhaitables pour la productivité. Elles représentent donc une bonne opportunité pour les selectionneurs d'améliorer les citrouilles et de sélectionner les germoplasmes.

Mots Clés: Cucurbita spp., IPGRI, diversité morphologique

\section{INTRODUCTION}

Pumpkins (Cucurbita spp.) are a group of plants that are taxonomically classified in the genus Cucurbita and family Cucurbitacea. The name pumpkin is usually used interchangeably to refer to both the plant and the fruit it produces. The most popular species of pumpkins that are cultivated are Cucurbita pepo (Howden, winter and ornamental gourds), Cucurbita moschata Duch (winter squash), Cucurbita maxima Duch (large fruited winter squash) Cucurbita mixta (green stripped cushaw) and Cucurbita ficifolia (Hadia et al., 2008).

Pumpkins are plants of great importance because they are of high nutritional value (Konopacka et al., 2010; Niewczas et al., 2014; Kim et al., 2016). The leaves, fruits, male flowers, tips of the vines and seeds of pumpkins are all consumed as food. Also, the plant has been used to treat various diseases as alternative medicine (Marcus and Grollman, 2002; Chen et al., 2005; Sarkar and Gucha 2008). In Austria and some countries of Eastern Europe, oil extracted from pumpkin seeds is usually exported to other countries to generate income. Continents such as America, Europe and Asia cultivate pumpkins on large scale mainly for animal feed; whereas in Africa cultivation of pumpkins is done by small scale farmers mostly for domestic consumption, and less often for commercial purposes.

Pumpkins are listed among the neglected and underutilised crops in Kenya. They are at a high risk of genetic erosion and even extinction. Some of the main contributing factors include less emphasis on improvement of the crop and protection against pests and diseases (Gotor and Irungu, 2010), negative perception associating pumpkins with food for primitive and poor countries (Chweya, 1997), change in feeding habits and switch to exotic vegetables (Smith and Eyzaguirre 2007). This calls for urgent need to conserve pumpkin varieties available. The objective of this study was to assess morphological diversity of pumpkins of western Kenya, using fruit characters to inform breeding and conservation programmes of the germplasms available for accurate, effective selection and improvement of the crop varieties.

\section{MATERIALS AND METHODS}

A total of eighty mature pumpkin fruit samples were collected from farms, gardens and vegetable vendors in Kisii (KSI), Kisumu (KSM), Homabay (HMB), Nyamira (NMR), Kakamega (KKG), Vihiga (VHG), Busia (BSA) and Bungoma (BGM) representing all the climatic zones of western Kenya. A snow ball method was applied to identify farmers and vegetable vendors with pumpkins. Observable morphological fruit characters used in this study were as described by Balkaya and Ergün (2008). Eight qualitative characters (fruit shape, fruit ribs, number of colours of outer coat, predominant fruit skin colour, secondary fruit skin colour, secondary fruit skin colour 
pattern, flesh colour and brightness of the fruit) and five quantitative characters (fruit weight, and fruit length. Others included diameter of the fruit, thickness of flesh and length/diameter ratio) of every fruit were recorded. IPGR descriptor for cucurbitacea (IPGRI, 2003) was used to guide on the scoring of the observed characters of the fruits. A reference colour chart was used to determine the colour of the fruit coat and inner flesh. Sample weights were measured using a weighing balance, before pumpkin fruits were cut into halves each, using a table knife; for measurement of fruit length, fruit diameter, flesh thickness, flesh colour and removal of seeds. A thirty centimeter ruler was used to measure fruit length, diameter and flesh thickness.

The morphological data obtained were analysed using agglomerative hierarchical clustering and principal component analysis tools in XLSTAT 2017 software. Principal component analysis (PCA) was done using Pearson's correlation matrix to compute the association that accounts for the thirteen fruit morphological characters in showing diversity. Eigen values and Eigen vectors were used to show the magnitude and direction of correlations between fruit characters and components, respectively. The squared cosines generated were used to indicate the fruit characters that had significantly contributed to each component; where high squared cosines values for fruit characters in individual principal components implied characters with more weight in defining those principal components. A dendrogram was generated using the Unweighted Pair Group
Method with Arithmetic Mean (UPGMA) agglomeration method. The type of proximity used was similarity based on Pearson correlation coefficient.

\section{RESULTS}

Principal component analysis. Morphological variations of pumpkins from western Kenya were well explained using Principal Component Analysis (PCA). The first four principle components $(\mathrm{F} 1, \mathrm{~F} 2, \mathrm{~F} 3$ and F4) turned out to be the most significant in explaining variation out of the thirteen, accounting for $73.85 \%$ of the total variation (Table 1). Squared cosine values of characters generated were used as a measure of their contribution in explaining variation in Principal Components.

Based on the squared cosine values, Principal Component F1 was defined by fruit ribs, primary fruit skin colour, secondary fruit skin colour pattern, fruit weight, fruit diameter and flesh thickness. Principal Component F2 was defined by fruit length, brightness of the fruit and fruit length to diameter ratio; while Principal Component F3 was defined by colours of outer coat and secondary fruit skin colour. Principal component F4 had more weight in shape of the fruit and colour of the flesh (Table 2).

A PCA scatter plot was generated using a combination of two Principal Components F1 and F2 that accounted for the highest percentage of variation $(50.19 \%)$ (Fig. 1). The scatter plot clearly showed the morphological diversity that existed among pumpkins varieties from western Kenya. The pumpkin

TABLE 1. Eigen values and percentage variabilities of principal components F1, F2, F3 and F4 of pumpkins from western Kenya

\begin{tabular}{lrrrr}
\hline & \multicolumn{1}{c}{ F1 } & F2 & \multicolumn{1}{c}{ F3 } & \multicolumn{1}{c}{ F4 } \\
\hline Eigen value & 4.220 & 2.305 & 1.829 & 1.25 \\
Variability (\%) & 32.463 & 17.728 & 14.068 & 9.59 \\
Cumulative (\%) & 32.463 & 50.190 & 64.259 & 73.85 \\
\hline
\end{tabular}


TABLE 2. Squared cosines of morphological characters in principle components F1, F2, F3 and F4 of pumpkins from western Kenya

\begin{tabular}{|c|c|c|c|c|}
\hline Variables & F1 & F2 & F3 & F4 \\
\hline Shape & 0.154 & 0.005 & 0.018 & 0.459 \\
\hline Ribs & 0.596 & 0.048 & 0.001 & 0.009 \\
\hline Colours of outer coat & 0.028 & 0.232 & 0.522 & 0.002 \\
\hline $1^{\circ}$ skin colour & 0.253 & 0.066 & 0.073 & 0.242 \\
\hline $2^{\circ}$ skin colour & 0.017 & 0.012 & 0.668 & 0.019 \\
\hline $2^{\circ}$ colour pattern & 0.320 & 0.074 & 0.248 & 0.008 \\
\hline Fruit weight & 0.763 & 0.070 & 0.012 & 0.016 \\
\hline Length & 0.034 & 0.685 & 0.073 & 0.088 \\
\hline Diameter & 0.766 & 0.023 & 0.069 & 0.013 \\
\hline Flesh colour & 0.172 & 0.077 & 0.001 & 0.325 \\
\hline Flesh thickness & 0.829 & 0.019 & 0.018 & 0.002 \\
\hline Brightness of fruit & 0.068 & 0.436 & 0.001 & 0.012 \\
\hline L/D ratio & 0.220 & 0.557 & 0.125 & 0.052 \\
\hline
\end{tabular}

Figures in bold represent significantly high values

Observations (axes F1 and F2: $50.19 \%$ )

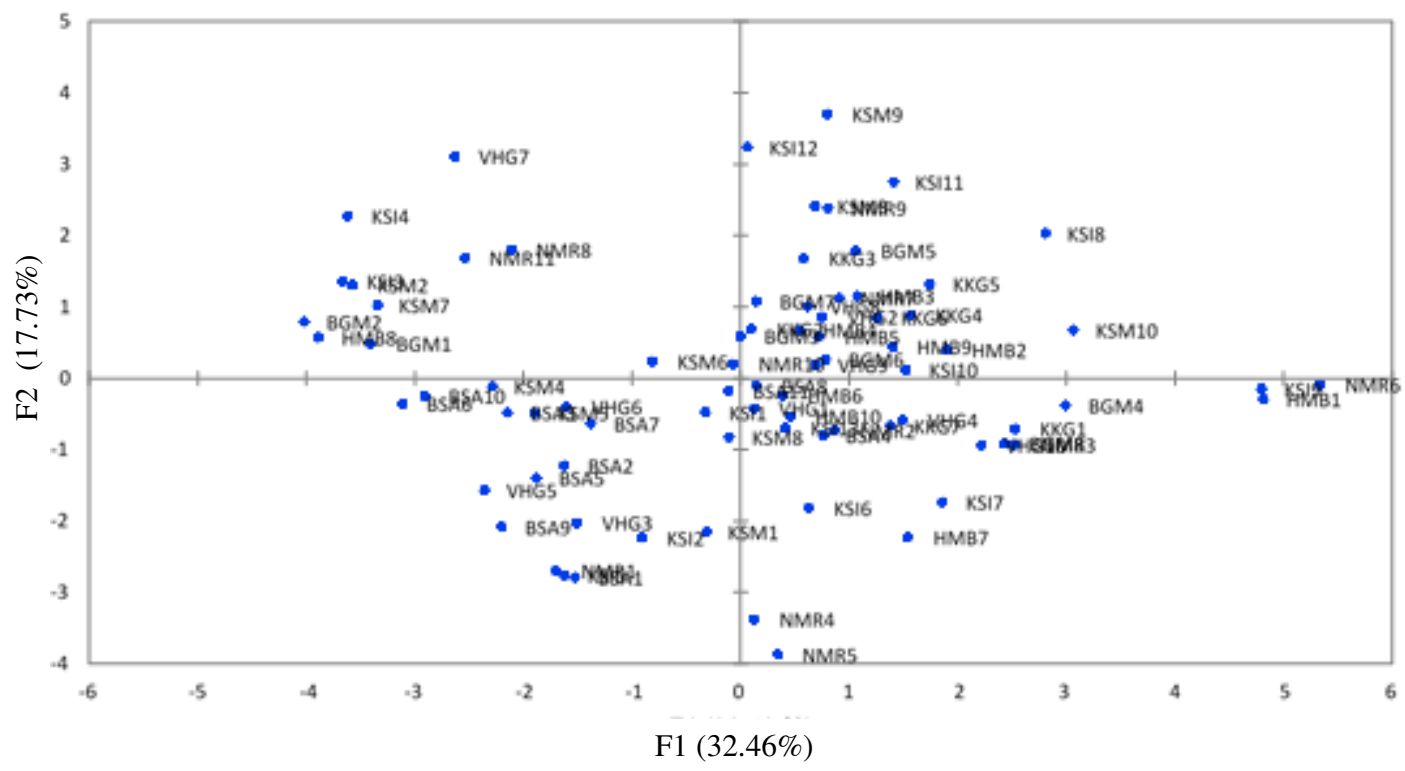

Figure 1. Principal component analysis scatter plot of PC F1 against PC F2 showing clustering of 80 pumpkin samples from western Kenya, using the thirteen morphological characters. 


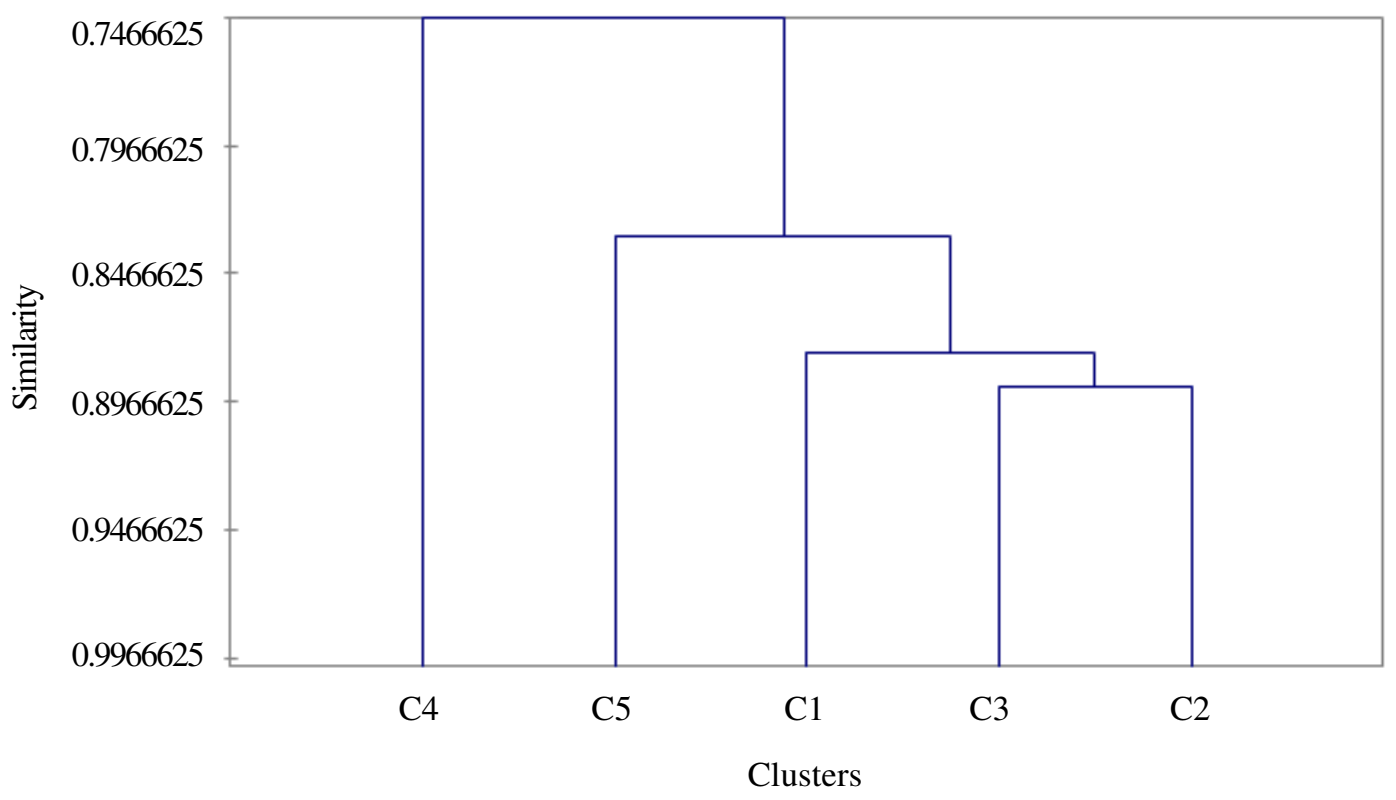

Figure 2a. Morphological similarity dendrogram of the 80 pumpkin fruit samples from western Kenya, showing the generated five clusters.

samples were scattered in all the four quartiles, with majority of the samples from all regions densely scattered in the upper and lower right quartiles; while a few were sparsely scattered in the upper and lower left quartile. A few individual samples scattered distantly away from other samples in all the four quartiles; indicating presence high amounts of morphological differences between them and the others.

Cluster analysis. Cluster analysis grouped the pumpkins into five main clusters (Fig. 2a). There was further grouping within clusters 1 , 2 and 3 (Fig. 2b); with more variations within the clusters rather than between the clusters. Majority of the samples fell into cluster 1, which had 57 samples; followed by cluster 2 with 19 samples; cluster 3 with 2 samples; and cluster 4 and 5 which had 1 sample each (Table 3).

\section{DISCUSSION}

Principal component analysis. Based on the scattering of the samples on the scatter plot in this study, PCA effectively showed morphological diversity among pumpkins from western Kenya using morphological characters of the fruits. This is in agreement with previous studies on morphological diversity of pumpkins (Ntuli et al., 2017). The yield characters that appeared in principal components that accounted for a greater percentage of the total variation were fruit weight, fruit diameter fruit length and flesh thickness. These characters were also observed in other studies where fruit yield characters were used, together with seed and plant growth characters to access morphological variation among Cucurbita spp. (Balkaya et al., 2010; Martins et al., 2015; Kiramana and Isutsa 2017; Ntuli et al., 2017). These fruit yield characters are very effective in discriminating between varieties of Cucurbita spp., and explaining variations (Norman et al., 2014); therefore, are the best suited for selection of pumpkins for germplasms and breeding programmes (Xiaohua et al., 2011; Mladenovic et al., 2014). They should also be used as priority characters in studies of morphological diversity, selection and effective utilisation of 


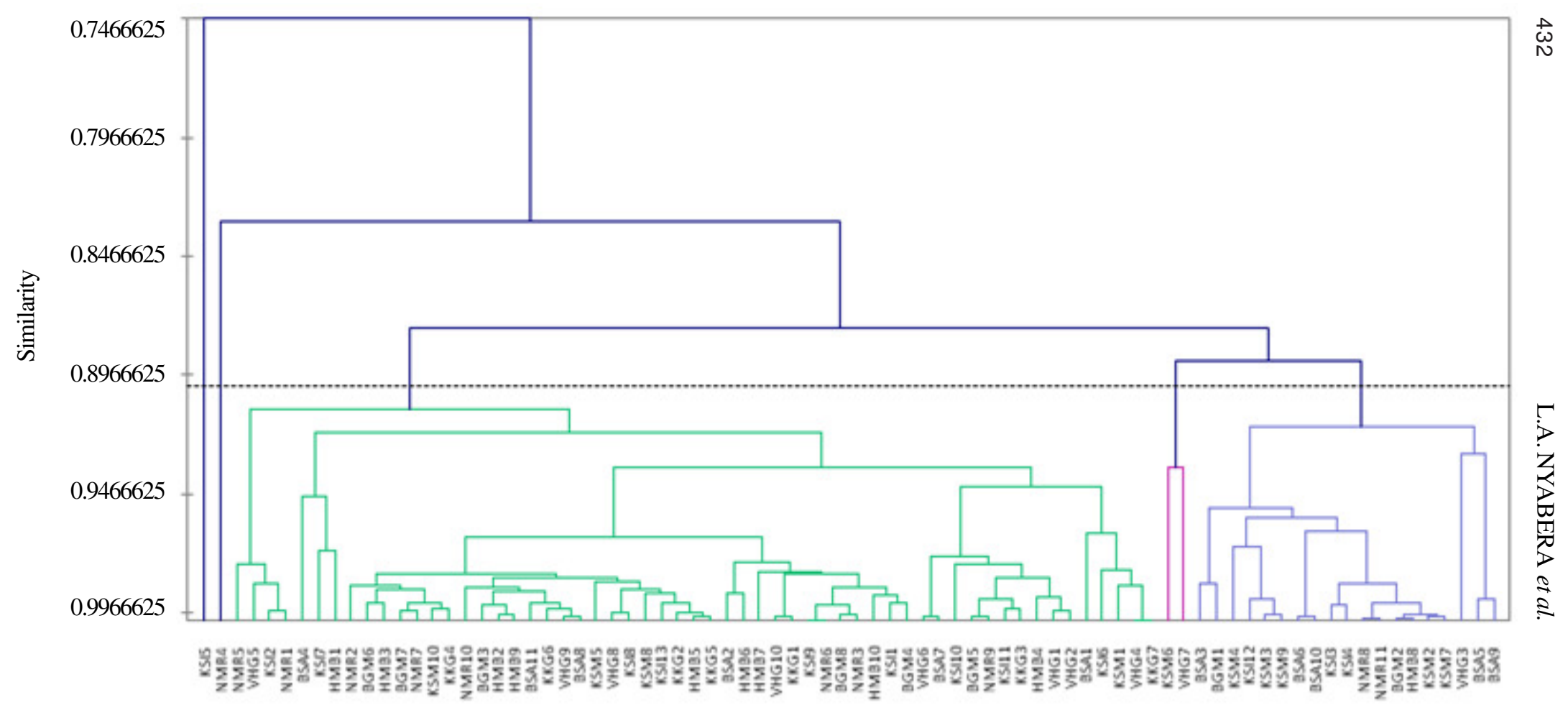

Figure 2b. Morphological similarity dendrogram of the 80 pumpkin fruit samples from western Kenya, generated by Unweighted Pair Group Method with Arithmetic Mean (UPGMA) based on Pearson correlation coefficient. 
TABLE 3. Distribution of the eighty pumpkin fruit samples from western Kenya in the five clusters

\begin{tabular}{lllll}
\hline Cluster 1 & Cluster 2 & Cluster 3 & Cluster 4 & Cluster 5 \\
\hline KSM1,KSM5,KSM10, & KSM2,KSM3,KSM4, & KSM6,VHG7 & KSI5 & NMR4 \\
VHG1,VHG2,VHG4, & KSM7,KSM9,VHG3, & & \\
VHG5,VHG6,VHG8 & BSA3,BSA5,BSA6, & & \\
VHG9,VHG10,BSA1, & BS9,BSA10,KSI3, & & \\
BSA2,BSA4,BSA7, & KSI4,KSI12,BGM1, & & \\
BSA8,BSA11,KSI1, & BGM2,NMR8,NMR11, & & \\
KSI2,KSI6,KSI7, & HMB8, & \\
KSI8,KSI9,KSI10, & & & \\
KSI1,KISI13,BGM3, & & & \\
BGM4,BGM5,BGM6, & & & \\
BGM7,BGM8,NMR1, & & \\
NMR2,NMR3,NMR5, & & \\
NMR6,NMR7,NMR9, & & \\
NMR10,HMB1,HMB2, & & \\
HMB3,HMB4,HMB5, & & \\
HMB6,HMB7,HMB9, & & \\
HMB10, KKG1,KKG2, & & & \\
KKG3,KKG4,KKG5, & & \\
KKG6,KKG7 & & \\
\hline
\end{tabular}

genetic resources of pumpkins. Mohsin et al. (2017) observed strong associations between fruit yield characters and plant productivity of pumpkins. Yield characters are highly heritable and their expression is not easily affected by environmental factors (Martins et al., 2016; Mohsin et al., 2017).

The PCA scatter plot (Fig. 1) strongly suggests that majority of pumpkins cultivated in western Kenya are morphologically similar, with some degree of variation among them. Three samples from Nyamira (NMR 6), Homabay (HMB 1) and Kisii (KSI 9) had high fruit weight of $5.1,5.2$ and $4.8 \mathrm{~kg}$, respectively; compared to other samples, making then scatter in one direction. This corresponds well with other findings that reported maximum fruit weight of $5 \mathrm{~kg}$ for Cucurbita moschata hybrids and $4.2 \mathrm{~kg}$ for Cucurbita moschata genotypes (Loy et al., 2004; Ahamed et al., 2012). One sample from Kisumu (KSM 9) had the greatest length of $32.6 \mathrm{~cm}$; however, reported fruit length for
Cucurbita landraces range from 27.4 to 38.9 cm (Ntuli et al., 2017).

Samples from Kisii and Nyamira scattered in all the four quartiles indicating highest diversity, which could be attributed to the good agricultural potential of these regions.

Cluster analysis. Cluster analysis suggest highest diversity in samples from Kisii, Nyamira, Vihiga and Kisumu, which appeared in three clusters out of five. Various studies have shown clustering of pumpkin samples from various geographical regions in the same clusters and sub clusters (Liu et al., 2013). Other factors that may lead to diversity are easy hybridising nature of Cucurbita spp. members, especially Cucurbita moschata; and trading of pumpkins in markets and exchange of seeds due to close proximity of geographical regions (Montes - Hernandez and Eguiarte, 2002; Ferriol et al., 2004). Even though Kisii, Nyamira and Vihiga geographical regions have similar highland climatic conditions, Kisumu 
experiences tropical humid climatic condition. The possible factor that may be influencing diversity of pumpkins in these regions is exchange of seeds mainly through trade rather than differences in climate. Additionally, other recent findings have shown that Cucurbitacea family exhibits wide variations in morphological characters (Mladenovic et al., 2014). Variations within clusters, therefore, give a good opportunity to breeders to improve closely related members by passing desirable traits such as high productivity and resistance to diseases and drought. Hybridising of closely related varieties is easier than distantly related ones.

\section{ACKNOWLEDGEMENT}

The authors thank the Department of Biochemistry and Biotechnology of Technical University of Kenya for providing laboratory working space. Mr. Peter Mwirigi of Kenyatta University assisted with data analysis.

\section{REFERENCES}

Balkaya, A. and Ergün, A. 2008. Diversity and use of pinto bean (Phaseolus vulgaris) populations from Samsun, Turkey. New Zealand Journal of Crop and Horticultural Science 36(3):189-197.

Balkaya, A., Özbakir, M. and Kurtar, E.S. 2010. The phenotypic diversity and fruit characterization of winter squash (Cucurbita maxima) populations from the Black Sea Region ofTurkey. African Journal of Biotechnology 9(2):152-162.

Chen, J.G., Liu, Z.Q., Wang, Y., Lai, W.Q., Mei, S. and Fu, Y. 2005. Effects of sugarremoved pumpkin zymptic powders in preventing and treating the increase of blood glucose in alloxan induced diabetic mice. Chinese Journal of Clinical Rehabilitation 9:94-95.

Chweya, J.A. 1997. Genetic enhancement of indigenous vegetables in Kenya. Traditional African Vegetables. International Plant
Genetic Resources Institute (IPGRI), Rome, Italy. pp. 86-95.

Ferriol, M., Pico, B., de Cordova, P. F. and Nuez, F. 2004. Molecular diversity of a germplasm collection of squash determined by SRAP and AFLP Markers. Crop Science 44(2):653-664.

Gotor, E. and Irungu, C. 2010. The impact of Bioversity International's African leafy vegetables programme in Kenya. Impact Assessment and Project Appraisal 28(1):41-55.

Hadia, H.A., Abdel-Razzak, H.S. and Hafez, E.E. 2008. Assessment of genetic relationships among and within Cucurbita species using RAPD and ISSR markers. Journal of Applied Science Research 4(5):515-525.

IPGRI. 2003. Descriptors for Cucumis melo L. International Plant Genetic Resources Institute, Rome, Italy.https://www. bioversityinternational.org/uploads/ tx_news/Descriptors_for_melon__ Cucumis_melo_L._906.pdf.

Kim, C.J., Kim, H.W., Hwang, K.E., Song, D.H., Ham, Y.K., Choi, J.H. and Choi, Y.S. 2016. Effects of dietary fiber extracted from pumpkin (Cucurbita maxima Duch.) on the physico-chemical and sensory characteristics of reduced-fat frankfurters. Korean Journal for Food Science of Animal Resources 36(3):309.

Kiramana, J.K. and Isutsa, D.K. 2017. Morphological characterization of naturalised pumpkin (Cucurbita moschata (Lam.) Poir.) accessions in Kenya. African Journal of Horticultural Science 12:61-83.

Konopacka, D., Seroczy’nska, A., Korzeniewska, A., Jesionkowska, K., Niemirowicz-Szczytt, K. and $\mathrm{P}^{3}$ ocharski, W. 2010. Studies on the usefulness of Cucurbita maxima for the production of ready-to-eat dried vegetable snacks with a high carotenoid content. LWT Food Science and Technology 43:302-309.

Liu, C., Ge, Y., Wang, D. J., Li, X., Yang, X. X., Cui, C.S. and Qu, S.P. 2013. 
Morphological and molecular diversity in a germplasm collection of seed pumpkin. Scientia Horticulturae 154:8-16.

Loy, J.B. 2004. Morpho-physiological aspects of productivity and quality in squash and pumpkins (Cucurbita spp.). Critical Reviews in Plant Sciences 23:337-363.

Marcus, D.M. and Grollman, A.P. 2002. Botanical medicines-the need for new regulations. The New England Journal of Medicine 347(25): 2073.

Martins, S., De Carvalho, C. R. and Carnide, V. 2015. Assessing phenotypic diversity of

Cucurbita Portuguese germplasm. Poljoprivredai Sumarstvo 61(1):27.

Martins, L.H.P., Noda, H., Lopes, M.T.G., Mendonça, M.S.P. and Martins, A.L.U. 2016. Genetic variability of pumpkin landraces in Brazilian Amazon. Agricultural Sciences 7(12):822-833.

Mladenoviæ, E., Berenji, J., Ognjanov, V., Ljubojeviæ, M., Ėukanoviæ, J. and Salamun, T. 2014. Genetic diversity in a collection of ornamental squash (Cucurbita pepo L.). Genetika 46(1):199-207.

Mohsin, G.M., Islam, M.S., Rahman, M.S., Ali, L. and Hasanuzzaman, M. 2017. Genetic variability, correlation and path coefficients of yield and its components analysis in pumpkin (Cucurbita moschata Duch Ex Poir). International Journal of Agricultural Research, Innovation and Technology 7(1):8-13.
Montes-Hernandez, S. and Eguiarte, L.E. 2002. Genetic structure and indirect estimates of gene flow in three taxa of Cucurbita (Cucurbitaceae) in western Mexico. American Journal of Botany 89(7):1156-1163.

Niewczas, J., Mitek, M., Korzeniewska, A. and Niemirowicz-Szczytt, K. 2014. Characteristics of selected quality traits of novel cultivars of pumpkin (Cucurbita Maxima Duch.). Polish Journal of Food and Nutrition Sciences 64(2):101-107.

Norman, P.E., Beah, A.A., Samba, J.A., Tucker, M.J., Benya, M.T. and Fomba, S.N. 2014. Agro-phenotypic characterization of sweet potato (Ipomoea batatas L.) genotypes using factor and cluster analyses. Agricultural Science Research Journal 4(2):30-38.

Ntuli, N.R., Madakadze, R.M. and Zobolo, A.M. 2017. Variation in morphology and yield traits of Cucurbita landraces in northern KwaZulu-Natal, South Africa. South African Journal of Plant and Soil 34(5):389-397.

Sarkar, S. and Guha, D. 2008. Effect of ripe fruit pulp extract of Cucurbita pepo Linn. in aspirin induced gastric and duodenal ulcer in rats. Indian Journal of Experimental Biology 46(9):639-645.

Xiaohua, D, Yongdong, S, Xinzheng, L, Junguo, Z. and Xiaomei, L. 2011. Genetic divergence among inbred lines in Cucurbita moschata from China. Scientia Horticulturae 127(3):207-213. 